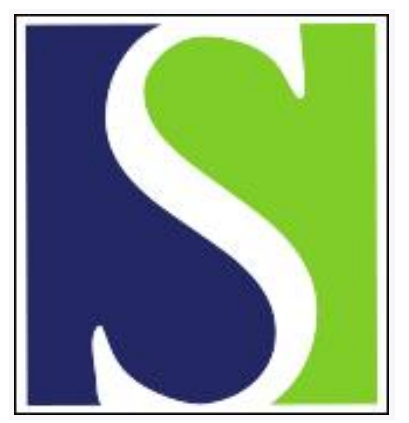

Scand J Work Environ Health 2009;35(3):222-232

https://doi.org/10.5271/sjweh.1327

Published online: 08 May 2009, Issue date: 00 May 2009

Self-reported versus expert-assessed work-relatedness of pain in the neck, shoulder, and arm

by Mehlum IS, Veiersted KB, Wærsted M, Wergeland E, Kjuus H

Affiliation: National Institute of Occupational Health, PO Box 8149 Dep, N-0033 Oslo, Norway. ism@stami.no

Refers to the following texts of the Journal: 2005;31(3):237-243

2007;33(3):165-191 2008;34(4):250-259 2001;27 suppl 1:1-102

Key terms: agreement; arm; clinical diagnosis; expert-assessment; exposure; health examination; MSD; musculoskeletal disorder; neck; occupational health; pain; questionnaire; risk evaluation; self-assessment; shoulder; upper extremity; work-relatedness

This article in PubMed: www.ncbi.nlm.nih.gov/pubmed/19430708 


\title{
Self-reported versus expert-assessed work-relatedness of pain in the neck, shoulder, and arm
}

\author{
by Ingrid Sivesind Mehlum, MD, ${ }^{1}$ Kaj Bo Veiersted, PhD, ${ }^{1}$ Morten Wærsted, PhD, ${ }^{1}$ Ebba Wergeland, \\ PhD, ${ }^{2}$ Helge Kjuus, $P h D^{1}$
}

\begin{abstract}
Mehlum IS, Veiersted KB, Wærsted M, Wergeland E, Kjuus H. Self-reported versus expert-assessed workrelatedness of pain in the neck, shoulder, and arm. Scand J Work Environ Health. 2009;35(3):222-232.

Objectives The aim of this study was to compare self-reported work-relatedness of neck-shoulder and arm pain with experts' assessments based on specific criteria.

Methods A sample of 217 employed participants in the Oslo Health Study 2000-2001, aged 30, 40, and 45 years, who reported neck-shoulder or arm pain in the past month, underwent a health examination. A criteria document for evaluating the work-relatedness of upper-extremity musculoskeletal disorders was used to establish clinical diagnoses and assess the work-relatedness of pain with respect to the subject's present job. We measured agreement between the participants and experts on whether pain was related to work as observed agreement, positive and negative specific agreement, and kappa.
\end{abstract}

Results A major proportion of the cases were assessed as work-related, somewhat more frequently by selfreport than when assessed by experts ( $80 \%$ versus $65 \%$ for neck-shoulder pain, and $78 \%$ versus $72 \%$ for arm pain, respectively). However, there was considerable disagreement as to which cases were work-related. The experts disagreed more frequently in cases that were reported as non-work-related (particularly for neck-shoulder pain and cases reported by men). Positive specific agreement was fairly high (76-85\% in the total population), while negative specific agreement was lower (37-51\%). Kappa values were also low (0.16-0.34).

Conclusions Compared with expert assessment, self-reporting did not seem to particularly exaggerate workrelatedness. Nevertheless, there was considerable disagreement, especially on cases assessed as non-workrelated. However, agreement will depend on the case definitions and the criteria for work-relatedness used both by the participants and the experts.

Key terms agreement; clinical diagnosis; expert-assessment; exposure; health examination; musculoskeletal disorder; occupational health; questionnaire; risk evaluation; self-assessment; upper extremity.

Self-administered questionnaires on work-related health problems are widely used, especially in population surveys (1-4), but also in more specific epidemiological studies (5-7). The validation of symptom reporting is often done when validating questionnaires $(8,9)$. However, self-assessment of work-relatedness has hardly been validated. Thus, although self-reported data may be easy to collect, they may be difficult to interpret as a measure of work-related illness in the population.

The definition of work-relatedness may differ according to purpose. If the aim is to prevent work-related illness, a wide definition may be preferable in order to prevent as much illness as possible $(10,11)$. The World Health Organization defines work-related diseases as multifactorial diseases, in which "the work environment and the performance of work contribute significantly, but as one of a number of factors to the causation" of the disease (page 9,12). For compensation purposes, a narrower definition is commonly used $(11,13)$. In order to be included in the British scheduled list of prescribed occupational diseases, a disease must "more likely than not" be caused by work, defined as a (more than) doubling of risk for a person in a particular job compared to someone not in that occupation (page 9,13).

The concept of work-relatedness may also differ among groups of people, for example, the general population versus physicians $(14,15)$. To our knowledge, only two studies comparing self-assessment and physician-assessment of work-relatedness have been published. Plomp (14) found hardly any relationship

1 National Institute of Occupational Health, Oslo, Norway.

2 Norwegian Labour Inspection Authority, Oslo, Norway.

Correspondence to: Dr IS Mehlum, National Institute of Occupational Health, PO Box 8149 Dep, N-0033 Oslo, Norway. [E-mail: ism@stami.no] 
between Dutch occupational physicians' and employees' judgment on the work-relatedness of health problems presented during a consultation hour. The British Health and Safety Executive (15) found that the treating doctor (usually the general practitioner) largely supported his patients' assessment of work-relatedness in a survey on self-reported work-related illness. Only cases reported as work-related were studied and, in $80 \%$ of the cases in which the doctor gave an opinion, work was considered "possibly", "probably", or "definitely" a cause of the illness. The results of the two studies are thus highly divergent, and the issue needs further exploration. The Oslo Health Study provided an opportunity to compare self-reported and expert-assessed work-relatedness based on a large population sample.

Musculoskeletal disorders are the most common health problem in the general population, and the health problem most often perceived as work-related $(5-7,15)$. These disorders are often chronic or recurrent, and are commonly associated with hazards both at and away from work. Clinical assessment of workrelatedness may, therefore, be particularly difficult (11). However, a group of European experts (10) has developed evidence- or consensus-based criteria for evaluating the work-relatedness of upper extremity musculoskeletal disorders (MSD); these criteria have been used in epidemiological studies $(16,17)$ and by occupational physicians in the Netherlands (18).

In a recent study, we demonstrated high prevalences of self-reported work-related health problems in the Oslo population (5). Among 8594 subjects, 38\% reported neck-shoulder pain while $20 \%$ noted pain in the elbow, forearm, or hand in the preceding month; nearly three in four reported their pain to be work-related (74\% and $72 \%$, respectively). Elsewhere, we have shown that occupational factors are important determinants of socio-economic inequalities in musculoskeletal pain in the working population of Oslo (19).

The aim of this study was to compare self-reported work-relatedness of neck-shoulder pain and arm pain with the assessments made by specialists in occupational medicine on the basis of criteria for evaluating the work-relatedness of upper extremity MSD (10).

\section{Study population and methods}

\section{Study population}

The study was part of the Oslo Health Study, a crosssectional population study conducted from May 2000 to September 2001 under the joint collaboration of the Norwegian Institute of Public Health, the University of Oslo, and the Municipality of Oslo. All individuals in Oslo county born in 1970, 1960, 1955, 1940-41, and 1924-25 were invited by letter to attend a health screening (20). Of the three youngest cohorts $(\mathrm{N}=26074$, aged 30, 40, and 45 years), 10712 attended the screening, and $8594(33 \%)$ returned an age-specific supplementary questionnaire, which included questions on work-related health problems (5), similar to the questions used by Statistics Norway in regular national surveys (21).

The introductory question was: "Have you experienced any of the following common health problems in the last month, and are they totally or partially caused by working conditions in your present or previous job?" This was followed by a list of 11 commonly work-related health problems, among them pain in neck or shoulder and pain in elbow, forearm, or hand (5). The response categories were: "No, I have not experienced this"; "Yes, but not caused by work"; and "Yes, totally or partially caused by work".

To evaluate the self-reported attribution of health problems to work, 668 subjects were invited to further health examinations at the Norwegian Institute of Occupational Health (NIOH). All subjects reporting work-related eczema or respiratory symptoms were invited ( $N=508), 68 \%$ of whom reported pain in the neck-shoulder or arm. In addition, 160 subjects were invited on the basis of their reported neck-shoulder pain or arm pain (pain in the elbow, forearm, or hand), and were selected consecutively after attending the Oslo Health Study, at two different points in time (100 subjects reporting work-related pain and 60 subjects reporting non-work-related pain). In order to protect personal health information, the Norwegian Institute of Public Health sent the invitations to the selected subjects, informing them of our study, and asking them for consent to give their name and contact information to the NIOH. Of the 668 invited subjects, 302 gave their consent and were subsequently contacted; 268 of these were examined between September 2000 and September 2002 by one of three participating physicians in the Department of Occupational Medicine at our institute. This study was restricted to the 217 employed subjects reporting neck-shoulder or arm pain in the past month, 142 women $(65 \%)$ and 75 men.

\section{Evaluation of work-relatedness of pain}

Prior to the health examination, the subjects completed a questionnaire on symptoms, occupational history, and working conditions. They answered once again the question on work-related health problems from the age-specific questionnaire of the Oslo Health Study, but with the work-related category subdivided into present and previous work. The physician checked the answers with the subject and relevant information was added. The health examination and evaluation process took 
approximately one hour. The procedure for assessing the work-relatedness of pain was based on the "Criteria Document for Evaluating the Work-Relatedness of Upper-Extremity Musculoskeletal Disorders" (hereafter referred to as the criteria document), published by a group of European experts (10). The document's main goal is prevention; it was designed to help the physician with the process of recognizing and diagnosing work-related upper extremity MSD in the clinical setting, but certain criteria may also be used at the workplace or community level. We used the criteria document to operationalize the concept of work-relatedness and ensure a consistent assessment throughout the study.

The criteria document consists of two parts: (i) establishing the clinical diagnosis, based on case definitions and diagnostic criteria for specific disorders, and (ii) assessing the work-relatedness of the diagnosis.

Subjects reporting pain in the neck-shoulder or arm in the past month were classified as having a clinical diagnosis if the following criteria were met: (i) temporal criteria: symptoms present at the examination or on at least 4 days during the past 7 days, (ii) symptom criteria for the relevant clinical diagnoses according to the region of pain, and (iii) sign criteria on relevant provocative tests, thoroughly described, with photos, in the criteria document.

One of the authors of this study trained the three physicians in performing the diagnostic provocative tests. The five most common clinical diagnoses were selected for the examination: (i) radiating neck complaints, (ii) rotator cuff syndrome, (iii) epicondylitis (lateral and medial), (iv) peritendinitis-tenosynovitis in the forearm-wrist, and (v) carpal tunnel syndrome.

In accordance with the criteria document, the physicians assessed the work-relatedness of pain in all the subjects, whether or not they had a clinical diagnosis, in the following four steps, which are outlined in table 1:

Step 1: temporal relationship: "Did the symptoms begin, recur or worsen after the current job started?" (Yes or No);
Step 2: occupational risk factors: exposure to work factors known to be specifically associated with MSD in the relevant body region (neck, shoulder-upper arm, elbow-forearm, or wrist-hand), based on scientific literature or the consensus of expert groups. Physical factors (posture, force, movement, and vibration), and non-physical factors (work organizational and psychosocial factors, such as work-rest ratio, psychological demands, and social support) were categorized into three risk zones: "unacceptable" (red), "not suitable" (yellow; situations for which no green or red delineation was possible, according to the criteria document), and "acceptable" (green).

Step 3: non-occupational risk factors: possible non-occupational origins for the symptom, for example, rheumatic diseases, leisure injuries, exposures (physical or psychosocial) outside of work, or hobbies (Yes or No).

Step 4: level of work-relatedness: final decision categorized into "probably work-related" (red = take action), "possibly work-related" (yellow = plan action), and "most likely not work-related" (green = no action).

The "traffic light model" (22) focuses primarily on preventive action, and has been used in regulations and guidelines (23). This model is suitable when the evidence for some risk factors are still lacking and no single work factor or combination of work factors can be said to be the sole cause of upper extremity MSD (10).

The subjects were interviewed about the temporal relationship and the risk factors. However, their answers were carefully considered by the physician, who made the final assessment. The evaluation of occupational risk factors in step 2 was based on specific criteria for each of the four upper extremity body regions, for example: (i) movement of the hands above shoulder height during a substantial part of the day - defined as $>2$ hours per workday - was, according to the criteria document, a physical risk factor for the shoulder-upper

Table 1. Procedure for evaluation of work-relatedness modified from the criteria document (10). Added or modified elements in italics.

\begin{tabular}{llll}
\hline Step 1 (time relation) & Step 2 (occupational risk factors) & Step 3 (non-occupational risk factors) & Step 4 (level of work-relatedness) \\
\hline Yes & Unacceptable (red) & Yes / no & Probably work-related (red) \\
Yes & Not suitable (yellow) ${ }^{\text {a }}$ & No & Probably work-related (red) \\
Yes & Not suitable (yellow) ${ }^{\text {a }}$ & Yes & Possibly work-related (yellow) \\
Yes & Acceptable (green) & Yes / no & Most likely not work-related (green) \\
No & Unacceptable (red) & Yes / no & Possibly work-related (yellow) \\
No & Not suitable (yellow) ${ }^{\text {a }}$ & No & Possibly work-related (yellow) \\
No & Not suitable (yellow) ${ }^{\text {a }}$ & Yes & Most likely not work-related (green) \\
No & Acceptable (green) & Yes / no & Most likely not work-related (green) \\
\hline
\end{tabular}

a "Not suitable" is, according to the criteria document, used for situations for which no green or red delineation is possible. 
arm region; and (ii) having insufficient recovery time per hour when highly repetitive movements are performed was a non-physical risk factor for all four body regions. This was defined as having $<10$ minute break within every 60 minutes of actions performed $>2-4$ times/minute, or in cycles of $<30$ seconds (10).

In evaluating the psychosocial working conditions, we used selected scales from the General Questionnaire for Psychological and Social factors at Work (QPSNordic) (24) instead of Karasek's Job Content Questionnaire (25), which was recommended in the criteria document. QPSNordic was developed to improve the scientific quality and usefulness of questionnaires on psychosocial factors at work; it is psychometrically tested and validated in the Nordic countries (24), and extensively used in Norway. Job control was not included in the criteria document, but we found this psychosocial dimension relevant for upper extremity MSD $(26,27)$. We thus used scales for the three occupational factors: (i) psychological job demands (10 items), (ii) job control (9 items), and (iii) social support at work (5 items). Each item was responded to on a five-point Likert scale. Scale scores in the upper quartile for psychological job demands, and in the lower quartile for social support were considered a risk, in accordance with the criteria document, as were scores in the lower quartile of the job control scale.

The procedure of the criteria document was somewhat modified (table 1: added or modified elements in italics). Firstly, the original procedure had no category for "not suitable" (yellow) in occupational risk factors (step 2) for the alterative of "no temporal relationship" (step 1). As we soon experienced the need for this, the category was added, using the same logic as for a positive temporal relationship. Secondly, in the original procedure a positive temporal relationship (step 1), without relevant occupational risk factors (step 2), with or without nonoccupational risk factors (step 3), led to the final decision of "possibly work-related" (yellow) in step 4. For example, a person with no known occupational risk factors, who had suffered a leisure injury in the upper extremity after starting his current job, and still experienced pain, would end up with a positive temporal relationship and thus be assessed as "possibly work-related". We found this unreasonable to our purpose, both in cases with and without non-occupational risk factors. We therefore modified the procedure to conclude with "most likely not work-related" in such cases.

In accordance with the criteria document, the occupational exposure (step 2) was rated "unacceptable" (red) in the presence of one or more physical risk factors for the relevant body region. If no physical risk factor was present, the occupational exposure was rated "acceptable" (green) in the absence of non-physical risk factors, and "not suitable" (yellow) when non-physical risk factors were present.

\section{Statistical analyses}

Before performing the analyses, the physicians' evaluations of risk factors were checked for inconsistencies with the criteria, without looking at the subjects' own assessments. According to the criteria document, the assessment of work-relatedness was based on the evaluation of ongoing exposure in the present job. Therefore, only pain reported caused by the present work was classified as "work-related", whereas pain reported to be caused by previous work $(\mathrm{N}=22)$ was classified as "non-workrelated". The fact that the latter group was comparable to the strict "non-work-related" group ( $\mathrm{N}=18)$, particularly on occupational risk factors for upper extremity MSD according to the criteria document, supported this classification. The study participants thus had two response categories: "work-related" and "not work-related", while the physicians had three: "probably work-related", "possibly work-related", and "most likely not work-related". Comparisons were made, with the physicians' "probably work-related" and "possibly work-related" categories combined as "work-related", as well as with the "possibly work-related" category omitted. We measured the agreement between subjects and physicians as observed agreement (ie, simple or raw agreement: the proportion of cases for which the raters agree), and positive and negative specific agreement (ie, the proportion of cases in a category, positive or negative, for which the raters agree), and calculated kappa (ie, chance-corrected agreement) (28). See the appendix for details. Analyses were performed using the statistical software SPSS 15.0 for Windows (SPSS Inc, Chicago, IL, USA).

The study protocol was approved by the Norwegian Data Inspectorate and recommended by the Regional Committee for Medical Research Ethics.

\section{Results}

\section{Self-reported work-relatedness of pain}

The presence of self-reported neck-shoulder pain and arm pain overlapped considerably among the 217 subjects (table 2). Nearly all reported neck-shoulder pain $(\mathrm{N}=208)$, while arm pain was somewhat less frequent $(\mathrm{N}=150)$, and almost two in three reported both $(\mathrm{N}=141)$. Work-related pain in at least one region was reported by 177 subjects (hereafter called the work-related group), while 40 subjects did not report any work-related pain (the non-work-related group). Subjects in the latter group were somewhat older and more frequently had a parttime job than subjects in the work-related group (table 3). Part-time work was more common among women than among men (18\% versus $5 \%)$, but the proportion of women was similar in both groups. 
The prevalence of region-specific physical risk factors for upper extremity MSD, according to the criteria document, was substantially higher in the work-related than in the non-work-related group, in particular risk factors for arm pain (table 3). Undertaking computer or mouse work most of the workday, and repetitive work with insufficient recovery time were somewhat more frequent in the work-related group. Differences in psychosocial working conditions were generally small. However, although the prevalence of high psychological demands was similar, the average level was higher in the work-related than in the non-work-related group (3.1 versus 2.8 ; range $1-5)$.

In both groups, approximately one in three had one or more clinical musculoskeletal diagnoses (table 3). Long duration of pain was more frequent in the non-work-related group; 38\% had pain lasting at least 15 years, compared to $18 \%$ among subjects reporting work-related pain. However, the latter group more often had co-workers with similar pain, and their pain improved much during vacations. There were minor differences with regard to the consequences of pain (table 3), except that subjects in the non-work-related group more frequently had changed their work. However, 10 of the 12 subjects with non-work-related pain who had changed their work, reported that their pain was caused by a previous job.

Within the work-related group, subjects who reported work-related pain in both the neck-shoulder and arm regions $(\mathrm{N}=107)$ differed somewhat from subjects who reported work-related neck-shoulder, but no arm, pain $(\mathrm{N}=52)$. The former group more frequently had physical risk factors in their work; $64 \%$ versus $45 \%$ had physical risk factors for neck pain, and $47 \%$ versus $24 \%$ had risk factors for shoulder pain. Computer or mouse work and repetitive work with insufficient recovery time were also more frequent (38\% versus 21\%, and 25\% versus $10 \%$, respectively). However, high psychological job demands seemed to be more frequent among subjects who reported work-related pain only in the neck-shoulder region (12\% versus $4 \%$ ).

Of the 217 subjects, 120 reported eczema (80 work-related) and 96 reported respiratory symptoms

Table 2. Distribution of subjects according to self-reported region and work-relatedness of pain, attributed to the present job.

\begin{tabular}{lcccr}
\hline & \multicolumn{3}{c}{ Arm } & \\
\cline { 2 - 4 } Neck-shoulder & $\begin{array}{c}\text { Work-related } \\
\text { pain }\end{array}$ & $\begin{array}{c}\text { Non-work- } \\
\text { related pain }\end{array}$ & No pain & Total \\
\hline Work-related pain & 107 & 8 & 52 & 167 \\
Non-work-related pain & 4 & 22 & 15 & 41 \\
No pain & 6 & 3 & 0 & 9 \\
\hline Total & 117 & 33 & 67 & 217 \\
\hline
\end{tabular}

(30 work-related). Perceived work-relatedness of these symptoms was more frequent in the work-related than in the non-work-related group: $41 \%$ versus $18 \%$ for eczema, and $15 \%$ versus $8 \%$ for respiratory symptoms.

Table 3. Background, exposure, and outcome-related variables among subjects with neck-shoulder or arm pain, according to selfreported work-relatedness in the present job. (\% is valid percent)

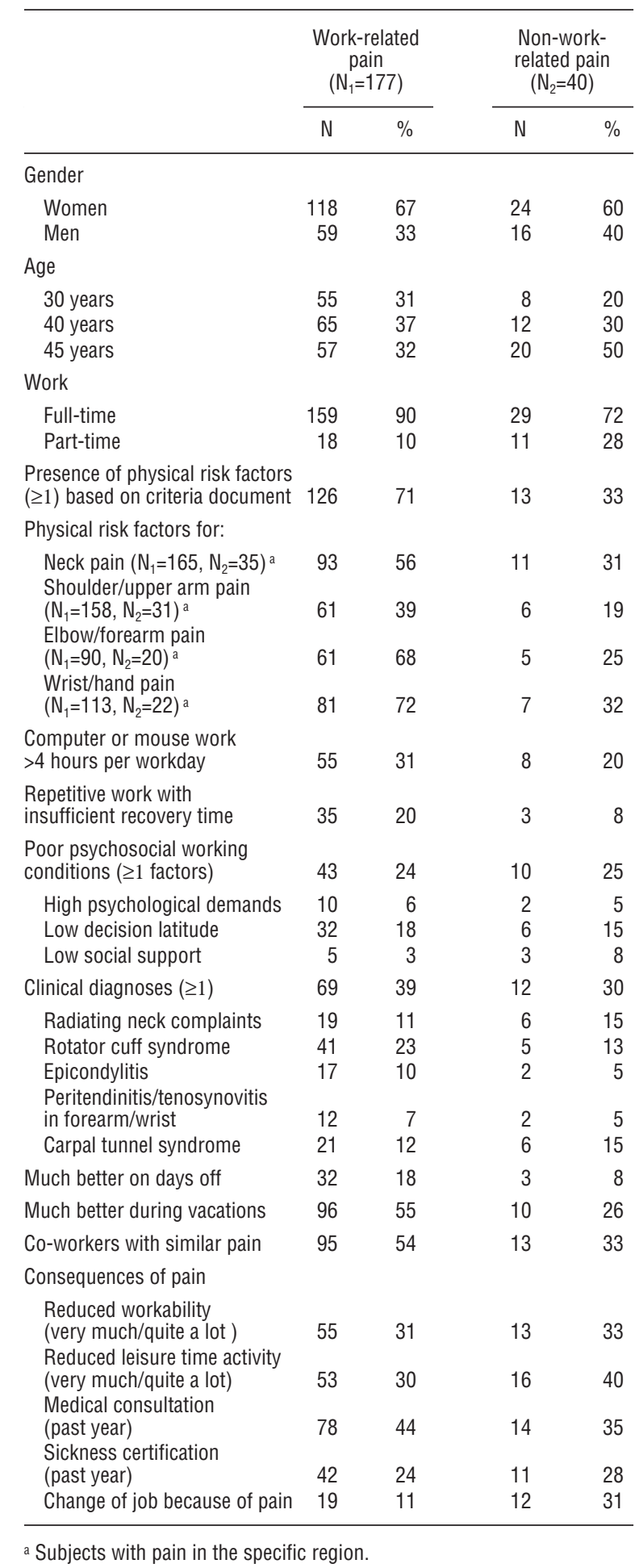




\section{Self-reported versus expert-assessment}

Among the 208 subjects with neck-shoulder pain, 167 $(80 \%)$ reported their pain to be work-related, while the experts assessed 136 cases $(65 \%)$ to be probably or possibly work-related (table 4). However, there was considerable disagreement as to which cases were work-related. Of the 167 cases reported by participants as work-related, the experts assessed $51(31 \%)$ to be not work-related. Of the 41 cases self-reported as not work-related, the experts assessed $20(49 \%)$ to be probably or possibly work-related; this was higher in men $(79 \%)$ than in women $(33 \%)$. However, the numbers are small, particularly in men.

Among the 150 subjects with arm pain, 117 (78\%) reported work-related pain, while the experts assessed 108 cases $(72 \%)$ to be probably or possibly work-related (table 5). There was somewhat less disagreement as to which cases were work-related than for neck-shoulder pain. Of the 117 cases reported as work-related, the experts assessed $24(21 \%)$ to be non-work-related. Of the 33 cases reported as non-work-related, the experts assessed $15(45 \%)$ to be probably or possibly workrelated $-58 \%$ in men and $39 \%$ in women.

The agreement between self-reported and expert-assessed work-relatedness was generally higher for arm pain than for neck-shoulder pain (table 6). The positive specific agreement was $74-88 \%$, while the negative was much lower, generally $37-52 \%$, but particularly low for neck-shoulder pain in men, which was approximately $20 \%$. Kappa values were fairly low, ranging between $-0.02-0.37$, and lowest for neck-shoulder pain in men, for whom the agreement

Table 4. Self-reported and expert-assessed work-relatedness of neck-shoulder pain among women and men and in the total population.

\begin{tabular}{|c|c|c|c|c|c|c|c|}
\hline \multirow[b]{3}{*}{ Self-reported } & \multirow[b]{3}{*}{$\mathrm{N}$} & \multicolumn{6}{|c|}{ Expert-assessed } \\
\hline & & \multicolumn{2}{|c|}{$\begin{array}{c}\text { Probably } \\
\text { work-related }\end{array}$} & \multicolumn{2}{|c|}{$\begin{array}{c}\text { Possibly } \\
\text { work-related }\end{array}$} & \multicolumn{2}{|c|}{$\begin{array}{c}\text { Not } \\
\text { work-related }\end{array}$} \\
\hline & & $\mathrm{N}$ & $\%$ & N & $\%$ & $\mathrm{~N}$ & $\%$ \\
\hline \multicolumn{8}{|l|}{ Women } \\
\hline Work-related & 112 & 62 & 55 & 12 & 11 & 38 & 34 \\
\hline Not work-related & 27 & 6 & 22 & 3 & 11 & 18 & 67 \\
\hline Total & 139 & 68 & 49 & 15 & 11 & 56 & 40 \\
\hline \multicolumn{8}{|l|}{ Men } \\
\hline Work-related & 55 & 37 & 67 & 5 & 9 & 13 & 24 \\
\hline Not work-related & 14 & 7 & 50 & 4 & 29 & 3 & 21 \\
\hline Total & 69 & 44 & 64 & 9 & 13 & 16 & 23 \\
\hline \multicolumn{8}{|l|}{ Total population } \\
\hline Work-related & 167 & 99 & 59 & 17 & 10 & 51 & 31 \\
\hline Not work-related & 41 & 13 & 32 & 7 & 17 & 21 & 51 \\
\hline Total & 208 & 112 & 54 & 24 & 12 & 72 & 35 \\
\hline
\end{tabular}

was no better than chance. When we included the "possibly work-related" category, compared with excluding it, the observed agreement and the positive specific agreement increased, while the negative specific agreement and the kappa value decreased. Among subjects with clinical diagnoses, all agreement measures were higher, with kappa values of 0.33 and

Table 5. Self-reported and expert-assessed work-relatedness of arm pain among women and men and in the total population.

\begin{tabular}{|c|c|c|c|c|c|c|c|}
\hline \multirow[b]{3}{*}{ Self-reported } & \multirow[b]{3}{*}{ N } & \multicolumn{6}{|c|}{ Expert-assessed } \\
\hline & & \multicolumn{2}{|c|}{$\begin{array}{c}\text { Probably } \\
\text { work-related }\end{array}$} & \multicolumn{2}{|c|}{$\begin{array}{c}\text { Possibly } \\
\text { work-related }\end{array}$} & \multicolumn{2}{|c|}{$\begin{array}{c}\text { Not } \\
\text { work-related }\end{array}$} \\
\hline & & $\mathrm{N}$ & $\%$ & $\mathrm{~N}$ & $\%$ & $\mathrm{~N}$ & $\%$ \\
\hline \multicolumn{8}{|l|}{ Women } \\
\hline Work-related & 74 & 44 & 59 & 12 & 16 & 18 & 24 \\
\hline Not work-related & 21 & 6 & 29 & 2 & 10 & 13 & 62 \\
\hline Total & 95 & 50 & 53 & 14 & 15 & 31 & 33 \\
\hline \multicolumn{8}{|l|}{ Men } \\
\hline Work-related & 43 & 33 & 77 & 4 & 9 & 6 & 14 \\
\hline Not work-related & 12 & 4 & 33 & 3 & 25 & 5 & 42 \\
\hline Total & 55 & 37 & 67 & 7 & 13 & 11 & 20 \\
\hline \multicolumn{8}{|l|}{ Total population } \\
\hline Work-related & 117 & 77 & 66 & 16 & 14 & 24 & 21 \\
\hline Not work-related & 33 & 10 & 30 & 5 & 15 & 18 & 55 \\
\hline Total & 150 & 87 & 58 & 21 & 14 & 42 & 28 \\
\hline
\end{tabular}

Table 6. Agreement measures comparing self-reported and expert-assessed work-relatedness of neck-shoulder pain and arm pain among women $(\mathrm{N}=142)$ and men $(\mathrm{N}=75)$, and in the total population ( $\mathrm{N}=217)$.

\begin{tabular}{|c|c|}
\hline Neck-shoulder pain & Arm pain \\
\hline $\begin{array}{cc}\begin{array}{c}\text { Possibly/ } \\
\text { probably }\end{array} & \begin{array}{c}\text { Probably } \\
\text { work- }\end{array} \\
\text { work- }^{2} & \text { related }^{\mathrm{b}} \\
\text { related }^{\mathrm{a}} & (\%) \\
(\%) & \end{array}$ & $\begin{array}{cc}\text { Possibly/ } & \text { Probably } \\
\text { probably } & \text { work- } \\
\text { work- } & \text { related d }^{\mathrm{d}} \\
\text { related } & (\%) \\
(\%) & \end{array}$ \\
\hline
\end{tabular}

Women

\begin{tabular}{lcccc} 
Observed agreement & 66 & 58 & 73 & 60 \\
Positive specific agreement & 77 & 74 & 82 & 79 \\
Negative specific agreement & 43 & 45 & 50 & 52 \\
Men & & & & \\
Observed agreement & 65 & 58 & 76 & 69 \\
Positive specific agreement & 81 & 79 & 88 & 87 \\
Negative specific agreement & 20 & 23 & 43 & 50 \\
Total population & & & & \\
Observed agreement & 66 & 58 & 74 & 63 \\
Positive specific agreement & 78 & 76 & 85 & 82 \\
Negative specific agreement & 37 & 40 & 48 & 51 \\
\hline
\end{tabular}

a Kappa $=0.23$ for women, -0.02 for men and 0.16 for total population. ${ }^{\mathrm{b}} \mathrm{Kappa}=0.25$ for women, 0.03 for men and 0.19 for total population.

${ }^{c} \mathrm{Kappa}=0.32$ for women, 0.29 for men and 0.31 for total population.

${ }^{\mathrm{d}} \mathrm{Kappa}=0.32$ for women, 0.37 for men and 0.34 for total population. 
Table 7. Differences in expert-assessed work-relatedness of neckshoulder pain and arm pain between using the modified and the original procedure of the criteria document.

\begin{tabular}{|c|c|c|c|c|}
\hline \multirow[b]{3}{*}{ Self-reported } & \multicolumn{4}{|c|}{ Expert-assessed } \\
\hline & \multicolumn{2}{|c|}{ Possibly work-related } & \multicolumn{2}{|c|}{ Not work-related } \\
\hline & $\begin{array}{l}\text { Modified } \\
\text { procedure }\end{array}$ & $\begin{array}{l}\text { Original } \\
\text { procedure }\end{array}$ & $\begin{array}{l}\text { Modified } \\
\text { procedure }\end{array}$ & $\begin{array}{c}\text { Original } \\
\text { procedure }\end{array}$ \\
\hline \multicolumn{5}{|l|}{ Neck-shoulder pain } \\
\hline Work-related & 17 & 54 & 51 & 14 \\
\hline Not work-related & 7 & 14 & 21 & 14 \\
\hline Total & 24 & 68 & 72 & 28 \\
\hline \multicolumn{5}{|l|}{ Arm pain } \\
\hline Work-related & 16 & 32 & 24 & 8 \\
\hline Not work-related & 5 & 12 & 18 & 11 \\
\hline Total & 21 & 44 & 42 & 19 \\
\hline
\end{tabular}

0.42 for neck-shoulder pain $(\mathrm{N}=60)$ and arm pain $(\mathrm{N}=27)$ respectively, excluding the "possibly workrelated" category.

Table 7 shows the differences in the experts' assessment of work-relatedness when using the modified versus the original procedure of the criteria document. As the modification did not influence the "probably workrelated" category, this was omitted from the table. If we had used the original procedure, 44 additional cases of neck-shoulder pain would have been assessed as possibly work-related (68 versus 24) instead of non-workrelated. The corresponding additional cases of arm pain would have been 23 (44 versus 21). This would have given somewhat higher agreement measures, with kappa values of 0.29 versus 0.16 for neck-shoulder pain including the "possibly work-related" category, and 0.39 versus 0.19 when excluding the category (data not shown). For arm pain, the corresponding kappa values would have been 0.31 (same value) and 0.45 versus 0.34 , respectively.

\section{Discussion}

Our comparative study included 217 Oslo citizens (aged 30, 40 and 45 years) who reported neck-shoulder pain or arm pain in the past month. A major proportion of these cases were assessed as work-related, although somewhat more frequently by the subjects than by the experts. However, there was considerable disagreement as to which cases were work-related. There was more agreement on arm pain than neckshoulder pain and generally more on cases assessed as work-related, as opposed to non-work-related ones, particularly in men.

\section{Methodological considerations}

The low participation in the Oslo Health Study may have led to self-selection of healthy individuals into the study. This would primarily have influenced the descriptive results, and has been thoroughly discussed elsewhere $(5,29)$. There were twice as many women as men among the subjects in our study, which may partly be explained by the facts that neck-shoulder pain and arm pain are more prevalent among women, and that women to a larger extent participated in the Oslo Health Study (5).

Thirty-four subjects consented to be contacted but were not examined, mainly because their symptoms were better or because they did not want an examination. The proportion of self-reported workrelated cases was somewhat higher in our study than in the Oslo Health Study; 91\% versus 74\% for neckshoulder pain and $90 \%$ versus $72 \%$ for arm pain, including cases caused by a previous job. However, we will not assume that self-selection of individuals with work-related pain significantly influenced comparisons between work-related and non-work-related pain, or between self-reported versus expert-assessed work-relatedness. The low attendance, particularly of subjects reporting non-work-related pain, led to small numbers in the stratified analyses, and thus uncertain results. The physicians were not blind to the subjects' assessments, which is a precondition for the measures of agreement employed. Employing formalized criteria for work-relatedness and checking for inconsistencies with the criteria without looking at the subjects' own assessments, may have reduced the interdependence of the two assessments. Subjects provided information on exposure which was evaluated by experienced physicians in occupational medicine. Objective exposure data are recommended by some, especially in cases of claims for financial compensation or legal issues (30). We share the view held by others that self-reported ergonomic exposures, in general, are adequate for epidemiologic purposes (31), and sufficiently accurate for our purpose.

Several factors may influence the attribution of illness to work, for example beliefs about disease etiology, a need to find an external explanation for symptoms, or a potential for economic compensation $(14,32)$. The subjects in our study had nothing to gain or to lose by attending the health examination, or reporting their pain as work-related or non-work-related. With the exception of hand-arm vibration syndrome, MSD are not eligible for compensation in Norway. The participating experts were independent of all stakeholders such as employers, employees/patients or insurance bodies (32), and met the subjects only once in relation to the research project. 


\section{Results}

Negative specific agreement and kappa values were generally low, with the latter below 0.40 , often defined as poor/slight $(<0.21)$ to fair $(0.21-0.40)$ agreement $(33,34)$. However, our sample was unbalanced, with low prevalences of non-work-related pain assessed by both subjects and experts. A severely unbalanced sample may lead to low kappa and low specific agreement in the rare category $(28,35,36)$.

If our sample (208 with neck-shoulder pain, 150 with arm pain) had been perfectly balanced, with an equal number of self-reported work-related and nonwork-related cases, and with the same percentage distribution of the experts' assessments as in the real sample, the kappa values would have been somewhat higher; 0.28 versus 0.19 for neck-shoulder pain and 0.42 versus 0.34 for arm pain, excluding the "possibly work-related" category. The corresponding values for negative specific agreement would have been substantially higher, $63 \%$ versus $40 \%$ and $68 \%$ versus $51 \%$, respectively. Thus, our unbalanced sample may have contributed to the fairly low agreement between the subjects and the experts.

The experts assessed as non-work-related quite a few conditions reported by the subjects as work-related. However, the experts assessed, as probably or possibly work-related, a larger proportion of conditions reported to be not work-related, especially in men. The positive specific agreement was thus higher than the negative, reflecting higher agreement on work-related than nonwork-related cases. This result is noteworthy, as one might anticipate self-report of work-relatedness to lead to overestimation rather than underestimation, compared with the experts' assessments. Both may, however, reflect differences between the experts' perspective and the lay perspective of the causes of illness (14). It is also worth keeping in mind that there is no "gold standard" in these cases.

We found higher agreement for arm pain than for neck-shoulder pain. The former may be more closely related to physical risk factors, and the latter to psychosocial factors, as indicated by our results, while the criteria document emphasizes physical risk factors more than psychosocial ones.

In our study, the experts disagreed more with men than women who reported their neck-shoulder pain as non-work-related. Men may be unaware of a possible connection between their work and pain, they may hesitate to report their pain as work-related, or they may see their pain as an inevitable part of their job, and consequently not worth reporting (37). On the other hand, reporting of work-related pain, with which the experts disagreed, was somewhat more frequent in women than in men. Force-demanding tasks have been found to be considerably more strenuous for females than males, which may explain excess musculoskeletal morbidity among females (38). Workplace design factors may be an important reason for gender differences in working technique (39). In our study, physical risk factors for upper extremity MSD, according to the criteria document, were somewhat more frequent in men $(73 \%$ had one or more) than in women (59\%). However, the criteria do not differentiate according to gender, and may thus underestimate the risk in women. In addition, a higher total workload in paid and unpaid work among women (39) may make them more vulnerable to lower levels of physical work exposure.

Subjects reporting work-related pain were somewhat younger than those reporting non-work-related pain, but age did not seem to be a consistent predictor of agreement between responder and expert (data not shown). Among subjects with clinical diagnoses, all agreement measures were higher. These subjects had positive provocative tests, in addition to their symptoms, and may represent a group with more serious pain conditions, for whom the association between work and pain was more evident to both the individual and the expert. Subjects reporting work-related eczema or respiratory symptoms more frequently reported workrelated pain also, but did not seem to exaggerate the work-relatedness of their pain (higher positive specific agreement; data not shown).

Eight individuals had encountered occupational injuries which still caused pain in the upper extremity region; seven of them reported their pain as work-related in the present job. Such cases are not captured by the criteria document, but may reasonably be considered as work-related. For these subjects, changing the final decision to the "probably work-related" category only marginally changed the agreement values.

\section{Work-relatedness}

Subjects who reported work-related pain had substantially higher prevalences of physical risk factors for upper extremity MSD in their work than those reporting non-work-related pain (table 3). Physical risk factors form a major part of the criteria for evaluation of work-relatedness, and the differences in these between the self-reported work-related and non-workrelated groups may be considered a separate measure of agreement.

A temporal relationship, with exposure before response, is essential in causal inference (40) and is considered a sine qua non for assuming causality (36). It was also considered important by the subjects, but not without exception; approximately $20 \%$ of the women and $15 \%$ of the men who reported work-related pain, did not report a positive time relationship (data not 
shown). On the other hand, approximately $85 \%$ of the subjects who did report such a relationship, assessed their pain to be work-related.

The concept of work-relatedness may differ according to context or purpose. Plomp (14) found somewhat higher agreement between occupational physicians and employees when the consultation was initiated by the physician (eg, because of absenteeism or a periodical medical examination) rather than the employee. He suggested that the potential socio-economic implications of the label of "work-relatedness of health problems" might be important, such as loss of job, reduction in income, or dispensation from specific types of work. An occupational physician, being salaried by the employer, may have a different position in relation to the employee/patient than a general practitioner. This may in part explain the different results found by Plomp (hardly any agreement) and by the British Health and Safety Executive (largely supportive of their patients' assessment) (15). Besides, differences in experience between occupational physicians and general practitioners, with respect to evaluation of work-relatedness, may lead to differences in assessments (42).

Our study's participants and the experts did not use the same response categories. The "possibly workrelated" category gave the experts an extra, less certain alternative, which the subjects did not have. On the other hand, the subjects were asked whether their pain was "totally or partially caused by working conditions", while the criteria document was based on evidence or consensus of a causal relation. Lower levels of work exposure, below the risk levels of the criteria, may not cause pain in healthy individuals or those with low exposure outside their work. They may, however, lead to an exacerbation of a pre-existing condition, the development of pain in an individual with a high total workload in paid and unpaid work (39), or the maintenance or recurrence of pain in subjects with work-related pain caused by a previous high risk job. Such cases would be assessed as work-related by the subject but non-work-related by the experts - correctly according to our criteria. Thus, the somewhat different criteria and response alternatives may have resulted in lower agreement in our study.

According to the procedure of the original criteria document, a positive time relationship, without relevant occupational risk factors, would lead to the final decision of a case being possibly work-related. This procedure would have resulted in considerably more cases being assessed as possibly work-related (table 7) and higher agreement values. The original procedure may capture some cases caused or made worse by exposure levels lower than the risk levels of the criteria, particularly in vulnerable individuals. According to the criteria document, further investigation of the "possibly work-related" cases is warranted (eg, observation of the work situation, or surveillance of the person over time) (10). This was beyond the scope of our study. We chose to modify the procedure of the criteria document to suit our needs. However, the original procedure may be reasonable when the purpose of the evaluation is the prevention of upper extremity MSD and further investigation is possible.

Using criteria in the assessment of work-relatedness may reduce subjectivity in judgments. However, we often found it difficult to evaluate exposures in work against the criteria, in particular repetitiveness in occupations with some degree of repetitive work, but not assembly work. We discussed this matter with the authors of the criteria document and found our judgments needed to be stricter. As a consequence, fewer cases were assessed as work-related. Others may have encountered the same problem. While $54 \%$ of neck-shoulder pain conditions and $58 \%$ of arm pain conditions were assessed as probably work-related in our study, $95 \%$ of upper extremity MSD cases in men and $89 \%$ in women ( $<50$ years), were classified as such in a study by Roquelaure et al (16), in which the criteria document was used. This may indicate discrepancies in the application of the criteria document and the need for further improvement and specification of the criteria.

\section{Concluding remarks}

Self-reported data is often used to follow population trends in work-related illness. Self-assessed workrelatedness of disease has been found to be an independent predictor of work disability (43), and may thus be of importance as such. However, the use of these data as a measure of work-related illness in the population has often been considered with skepticism, assuming it would result in exaggerated estimates. The British Health and Safety Executive (15) performed a case review to identify and exclude cases which were clearly not work-related, and concluded that their prevalence estimates based on self-reported work-related diseases could be reduced by $24 \%$. However, they did not evaluate cases reported as non-work-related to adjust for potential under-reporting.

Our results indicate that prevalence estimates based on self-report may be more valid than previously assumed with regard to neck-shoulder pain and arm pain. Compared with the assessment of experts, self-reporting did not seem to particularly exaggerate work-relatedness. However, there was considerable disagreement between the subjects and experts in individual cases. Agreement was higher for cases assessed as work-related compared to those categorized as non-work-related, and higher for arm pain than for neck-shoulder pain. Studies of other disease categories (15), or other age or cultural groups may yield different results, and need to be performed. 
Several factors, in addition to true disagreement, contributed to low agreement values, including an unbalanced sample and different response categories for subjects and experts.

Agreement will depend on the criteria by which the subjects and the experts evaluate work-relatedness. When we included the cases assessed by the experts to be possibly work-related in our analyses, the agreement values changed (compared to excluding such cases); this was also the case when using the modified procedure of the criteria document as opposed to the original. Both might influence to what extent cases made worse by work are included as work-related. Agreement will also depend on the case definition, illustrated by higher agreement for clinical diagnoses than for all cases of self-reported pain. The fact that a large proportion of reported non-work-related cases were attributed to a previous job, raises the issue that, with a wider definition, most cases of neck-shoulder and arm pain might actually be considered as work-related.

\section{Acknowledgements}

This study was supported financially by The Confederation of Norwegian Business and Industry's Working Environment Fund (Oslo, Norway) and The Directorate of Labour Inspection (Oslo, Norway). The primary data collection was conducted as part of the Oslo Health Study 2000-2001 in collaboration with the Norwegian Institute of Public Health, which also administered the invitations to the subjects selected for our study. We would like to thank Helge Jansson, MD, for examining 18 of the included subjects while working at the $\mathrm{NIOH}$, and members of the Veiersted family (Janne, Andreas, and Julie), for entering the data.

\section{References}

1. Statistics Norway. Level of living survey 2006: work conditions. Oslo: Statistics Norway; 2007.

2. Tynes T, Eiken T, Grimsrud TK, Sterud T, Aasnæss S. Arbeidsmiljø og helse - slik norske yrkesaktive opplever det: resultater fra Statistisk sentralbyrås levekårsundersøkelse for 2006 [Work environment and health - as experienced by working Norwegians: results from the Level of living survey 2006 from Statistics Norway]. Oslo: National Institute of Occupational Health; 2008. STAMI-rapport, number 16.

3. Parent-Thirion A, Fernández Macías E, Hurley J, Vermeylen G. Fourth European Working Conditions Survey. Dublin: European Foundation for the Improvement of Living and Working Conditions; 2007.
4. Health and Safety Executive (HSE). Self-reported work-related illness and workplace injuries in 2006-07: results from the Labour Force Survey. Caerphilly (United Kingdom): HSE; 2008.

5. Mehlum IS, Kjuus H, Veiersted KB, Wergeland E. Selfreported work-related health problems from the Oslo Health Study. Occup Med (Lond). 2006;56:371-9.

6. Räsänen K, Notkola V, Husman K. Perceived work conditions and work-related symptoms among employed Finns. Soc Sci Med. 1997;45:1099-110.

7. Thorslund M, Wärneryd B, Östlin P. The work-relatedness of disease: workers' own assessment. Sociol Health Illn. 1992;14:57-72.

8. Perreault N, Brisson C, Dionne C, Montreuil S, Punnett L. Agreement between a self-administered questionnaire on musculoskeletal disorders of the neck-shoulder region and a physical examination. BMC Musculoskeletal Disorders 2008;9:34.

9. Torén K, Brisman J, Järvholm B. Asthma and asthma-like symptoms in adults assessed by questionnaires. A literature review. Chest 1993;104:600-8.

10. Sluiter JK, Rest KM, Frings-Dresen MHW. Criteria document for evaluating the work-relatedness of upper-extremity musculoskeletal disorders. Scand J Work Environ Health. 2001;27 suppl 1:1-102.

11. Chen Y, Agius R, McNamee R, Turner S, Taylor S, Fulluck L, et al. Physicians' beliefs in the assessment of work attribution when reporting musculoskeletal disorders. Occup Med (Lond). 2005;55:298-307.

12. World Health Organization (WHO). Identification and control of work-related diseases: report of a WHO Expert Committee. Geneva: WHO; 1985. Technical Report Series, number 714.

13. Department for Work and Pensions (DWP). Completion of the review of the scheduled list of prescribed diseases: report by the Industrial Injuries Advisory Council in accordance with Section 171 of the Social Security Administration Act 1992 marking the completion of the review of the scheduled list of prescribed diseases. London: DWP; 2007.

14. Plomp HN. Employees' and occupational physicians' different perceptions of the work-relatedness of health problems: a critical point in an effective consultation process. Occup Med (Lond). 1993;43 suppl 1:S18-S22.

15. Jones JR, Hodgson JT, Clegg TA, Elliott RC. Self-reported workrelated illness in 1995: results from a household survey. Norwich (United Kingdom): Her Majesty's Stationery Office; 1998.

16. Roquelaure $\mathrm{Y}, \mathrm{Ha}$ C, Leclerc A, Touranchet A, Sauteron M, Melchior M, et al. Epidemiologic surveillance of upper-extremity musculoskeletal disorders in the working population. Arthritis Rheum. 2006;55:765-78.

17. Melchior M, Roquelaure Y, Evanoff B, Chastang JF, Ha C, Imbernon $\mathrm{E}$, et al. Why are manual workers at high risk of upper limb disorders? The role of physical work factors in a random sample of workers in France (the Pays de la Loire study). Occup Environ Med. 2006;63:754-61.

18. Spreeuwers D, Pal T, van der Laan G, editors. Signaleringsrap port Beroepsziekten '07 [Alert report on occupational diseases '07]. Amsterdam: Dutch Center for Occupational diseases, 
Coronel Institute of Occupational Health, Academic Medical Center, University of Amsterdam; 2007.

19. Mehlum IS, Kristensen P, Kjuus H, Wergeland E. Are occupational factors important determinants of socioeconomic inequalities in musculoskeletal pain? Scand J Work Environ Health. 2008;34(4):250-9.

20. Norwegian Institute of Public Health. The Oslo Health Study [Internet]. Oslo: Norwegian Institute of Public Health [updated June 2008, cited 18 December 2008]. Available from: http:// www.fhi.no/eway/default.aspx?pid=238\&trg=MainLeft_ 5853\&MainArea_5811 =5853:0:15,2818:1:0:0:::0:0\& MainLeft_5853=5825:54464::1:5857:4:::0:0

21. Statistics Norway. Survey of living conditions 2000: working environment. Oslo: Statistics Norway; 2001.

22. Andersen V, Bjurvald M, editors. Vägar till färre arbetsskador - utveckling av nordisk ergonomitillsyn, modeller för ergonomisk riskvärdering [How to reduce work injuries - development of Nordic ergonomic labour inspection, models for ergonomic risk assessment]. Copenhagen: Nordic Council of Ministers; 1994. TemaNord 1994:514.

23. Norwegian Labour Inspection Authority. Veiledning til forskrift om tungt og ensformig arbeid [Guidlines to the regulations on heavy and monotonous work]. Trondheim: Norwegian Labour Inspection Authority; 1995.

24 Dallner M, Elo AL, Gamberale F, Hottinen V, Knardahl S, Lindström K, et al. Validation of the General Nordic Questionnaire (QPSNordic) for psychological and social factors at work. Copenhagen: Nordic Council of Ministers; 2000. Nord 2000:12.

25. Karasek R. Job demands, job decision latitude and mental strain: implications for job redesign. Adm Sci Q. 1979;24:285-308.

26. Palmer KT, Smedley J. Work relatedness of chronic neck pain with physical findings - a systematic review. Scand J Work Environ Health. 2007;33(3):165-91.

27. Ariëns GA, van Mechelen W, Bongers PM, Bouter LM, van der Wal G. Psychosocial risk factors for neck pain: a systematic review. Am J Ind Med. 2001;39:180-93.

28. Hripcsak G, Heitjan DF. Measuring agreement in medical informatics reliability studies. J Biomed Inform. 2002;35:99-110.

29. Søgaard AJ, Selmer R, Bjertness E, Thelle D. The Oslo Health Study: the impact of self-selection in a large, population-based survey. Int J Equity Health. 2004;3:3.

30. Kuiper JI, Burdorf A, Frings-Dresen MH, Kuijer PP, Spreeuwers D, Lötters FJ et al. Assessing the work-relatedness of nonspecific low-back pain. Scand J Work Environ Health 2005;31(3):237-43.

31. Punnett L, Wegman DH. Work-related musculoskeletal disorders: the epidemiologic evidence and the debate. J Electromyogr Kinesiol 2004;14:13-23.

32. Dembe AE. Occupation and disease: how social factors affect the conception of work-related disorders. New Haven (CT): Yale University Press; 1996.

33. Landis JR, Koch GG. The measurement of observer agreement for categorical data. Biometrics. 1977;33:159-74.

34. Altman DG. Practical statistics for medical research. London: Chapman and Hall; 1991. p 403-9.
35. Feinstein AR, Cicchetti DV. High agreement but low kappa: I. The problems of two paradoxes. J Clin Epidemiol. 1990;43:543-9.

36. Cicchetti DV, Feinstein AR. High agreement but low kappa: II. Resolving the paradoxes. J Clin Epidemiol. 1990;43:551-8.

37. Pransky G, Snyder T, Dembe A, Himmelstein J. Under-reporting of work-related disorders in the workplace: a case study and review of the literature. Ergonomics 1999;42:171-82.

38. Nordander C, Ohlsson K, Balogh I, Hansson GA, Axmon A, Persson R, et al. Gender differences in workers with identical repetitive industrial tasks: exposure and musculoskeletal disorders. Int Arch Occup Environ Health. 2008;81:939-47.

39. Dahlberg R, Karlqvist L, Bildt C, Nykvist K. Do work technique and musculoskeletal symptoms differ between men and women performing the same type of work tasks? Appl Ergon. 2004;35:521-9.

40. Hill AB. The environment and disease: association or causation? Proc R Soc Med. 1965;58:295-300.

41. Rothman KJ, Greenland S, Poole C, Lash TL. Causation and causal inference. In: Rothman KJ, Greenland S, Lash TL, editors. Modern epidemiology. 3rd ed. Philadelphia (PA): Lippincott, Williams \& Wilkins; 2008. p 5-31.

42. O’Neill E, McNamee R, Agius R, Gittins M, Hussey L, Turner S. The validity and reliability of diagnoses of work-related mental ill-health. Occup Environ Med. 2008;65:726-31.

43. Martimo KP, Varonen H, Husman K, Viikari-Juntura E. Factors associated with self-assessed work ability. Occup Med (Lond). 2007;57:380-2.

Received for publication: 22 December 2008

\section{Appendix : Definition of agreement measures $(28,36)$}

\begin{tabular}{lccc}
\hline & \multicolumn{2}{c}{ Rater B } & \\
\cline { 2 - 3 } Rater A & Pos & Neg & Total \\
\hline Positive & $\mathrm{a}$ & $\mathrm{b}$ & $\mathrm{g}_{1}$ \\
Negative & $\mathrm{c}$ & $\mathrm{d}$ & $\mathrm{g}_{2}$ \\
\hline Total & $\mathrm{f}_{1}$ & $\mathrm{f}_{2}$ & $\mathrm{~N}$ \\
\hline
\end{tabular}

Observed agreement $=\frac{\mathrm{a}+\mathrm{d}}{\mathrm{N}}$

Positive specific agreement $=\frac{\mathrm{a}}{\frac{\mathrm{f}_{1}+\mathrm{g}_{1}}{2}}=\frac{2 \mathrm{a}}{2 \mathrm{a}+\mathrm{b}+\mathrm{c}}$

Negative specific agreement $=\frac{2 d}{b+c+2 d}$ 